\title{
Establishing geotechnical processes for improved mine design at Bulyanhulu
}

\author{
RM Stephenson AMC Consultants Pty Ltd, Australia \\ GC Chilala Acacia Mining plc, Tanzania \\ R Harris Acacia Mining plc, Tanzania \\ O Watson AMC Consultants Pty Ltd, Australia
}

\begin{abstract}
A combination of numerical and empirical design methods are employed for geotechnical input to mine design at Bulyanhulu, a narrow vein underground mining operation in Tanzania. Longhole open stoping, drift-and-fill, and Alimak stoping methods are currently in use.

Geotechnical design methods for longhole open stoping were refined and documented in a procedure to achieve a standardised approach. The procedure incorporates streamlined methods for data collection to make the best use of diamond drill hole logging, geological, and geotechnical mapping. Methods of back-analysis are also incorporated in the geotechnical designs.

In order to be effective, the procedure was implemented concurrently with a broader improvement project that focused on all aspects of the geotechnical engineering systems and processes. The project aimed to improve and streamline all geotechnical functions, to develop sustainable work processes within the geotechnical group and integration with other technical groups.

This paper discusses the implementation of the improvement programme and the impact on the success of geotechnical designs. The programme addresses group organisation, procedures and management plans, geotechnical analysis, reporting, and the implementation of geotechnical design into mine planning. A discussion is included on the measurement of geotechnical designs using monitoring and quality assurance/quality control (QA/QC).
\end{abstract}

\section{Introduction}

Effective mine designs require a collaborative effort within technical services between geology, mining engineering, and geotechnical engineering. The mining department, those executing the design, also play a vital role in the mine design by providing feedback. Likewise, technical services can measure the performance and execution of the designs and provide this feedback to the mining department. Mine designs can be improved and optimised with effective communication, and this cycle of design, execution, measurement, and feedback should be ongoing. Change is constant: personnel with their ideas, expertise, skills, management, motivation, and perceptions; and ground conditions as mining advances to greater depths and greater degree of extraction adding to the challenge. Employing a well-documented and standardised approach is essential to ensure a coherent, consistent and efficient system.

The systems and processes that must exist within a technical services department need to be current and well understood by the various sections and their management. It is important that this is well documented with management plans. They describe why things are done in a certain way and the history leading up to it, typically starting with a feasibility study. Procedures are referenced in the management plan and cover the specifics of executing certain tasks vital to the operation of that section. The purpose of both the management plans and procedures are to ensure that mining is executed safely and efficiently. 
Following the results of an internal high-impact function (HIF) audit for geotechnical considerations underground (Department of Mines and Petroleum, Western Australia), a project was undertaken at Bulyanhulu to enhance the systems and processes within the geotechnical engineering section. The major aims of the project were the improvement of mine design and sustainability of the section. The project also aimed to achieve more effective communication, efficiency and to work more closely with the other sections.

\subsection{Bulyanhulu Mine}

Bulyanhulu is located in the Shinyanga region in the northwest of Tanzania. It is a narrow vein underground gold mine using longhole open stoping, Alimak stoping, and drift and fill mining methods. The focus for the mine is to become fully mechanised with only the longhole open stoping mining method to minimise the different machinery required, simplify the mine planning process, and reduce risk to personnel of entry mining methods.

The current extent of mining is 2,000 m along strike and 1,170 m down-dip, to a depth of $1,240 \mathrm{~m}$ below surface. The mine has been in operation for 13 years and the current mine life is planned to be at least another 25 years.

The orebody dips at 75 to $85^{\circ}$ towards mine grid north and the high grade shoots plunge towards the west in Reef 1 and the east in Reef 2. There are three parallel reefs approximately 300 m apart (Reefs 0,1 and 2). Reefs 0 and 1 have been mined extensively and mining on Reef 2 has been undertaken in the upper areas.

The host rocks consist of a volcanic and sedimentary sequence. Mafic and felsic extrusive and intrusive rocks are intercalated with argillaceous sediments. All units have undergone greenschist facies metamorphism.

Mineralisation is hosted within quartz reefs of variable rock mass quality. The reefs are comprised of argillites, siliceous argillites, sheared argillites, or quartz massive sulphides. The hanging wall is typically ash tuff and the footwall typically basalt or argillite (Chamberlain 2003).

Several large-scale fault and dykes intersect the orebody, usually at a low angle as to appear almost sub-parallel to it. The faults can be characterised by highly sheared material. The dolerite dykes are typically blocky and have a considerably higher stiffness compared with the reef. Quartz-feldspar porphyry dykes are also noted in some areas of the mine.

The mine is divided into panels that currently employ either longhole open stoping, alimak stoping, or drift and fill mining methods. The longhole stoping panels are mined towards a central closure pillar with a mining front of $45^{\circ}$. These panels have been mined using an overhand method in the past and are now changing to an underhand method. High stresses requiring enhanced ground control are experienced at the stoping front, particularly towards the end of a panel sequence.

Mining panels are typically mined to almost $100 \%$ extraction using paste backfill. 'Non-pay' pillars have been left unmined, rib pillars have been left in some areas, and regional sill pillars of variable thickness are left every $150 \mathrm{~m}$. In the lower mining areas, the sill pillars are designed at a height of 25 to $30 \mathrm{~m}$.

Levels of seismicity are typically low but larger events have occurred on several occasions during the past five years of monitoring. Monitoring is conducted using an IMS seismic system with eight sensors and two geophysical seismometer boxes. The system is soon to be expanded from 8 to 20 geophones for greater coverage of the lower mining areas.

\section{Project methodology}

Prior to commencement of the enhancement project the geotechnical section collected adequate amounts of good quality data for rock mass classification, conducted ground support QA/QC, and conducted monitoring of the rock mass response to mining through seismic and displacement monitoring. The data was stored in various formats and was generally not being used for analysis. As part of the project, these 
processes were revised to progress towards a situation whereby the data collected is readily accessed for analysis and reported to the right people without requiring further resources.

The following steps were taken to complete the project:

- Review of the current capabilities and organisation of the geotechnical section, including the development of a skills matrix.

- Review of the current processes and gap analysis.

- Compilation of a workflow diagram.

- Listing of the documentation required for each step in the workflow diagram.

- Compilation of procedures for each process that are compatible with other departments and existing processes.

- Compilation of databases and reports to a set format to maintain consistency.

- Training and coaching of staff to implement the new procedures.

- Review of management plans to reflect the new systems and processes.

The geotechnical workflow diagram was compiled to incorporate all processes in the geotechnical section. This was also included in the introduction of each procedure to illustrate where that task is positioned in the overall geotechnical workflow, as illustrated in Figure 1 for QA/QC of ground support installation.

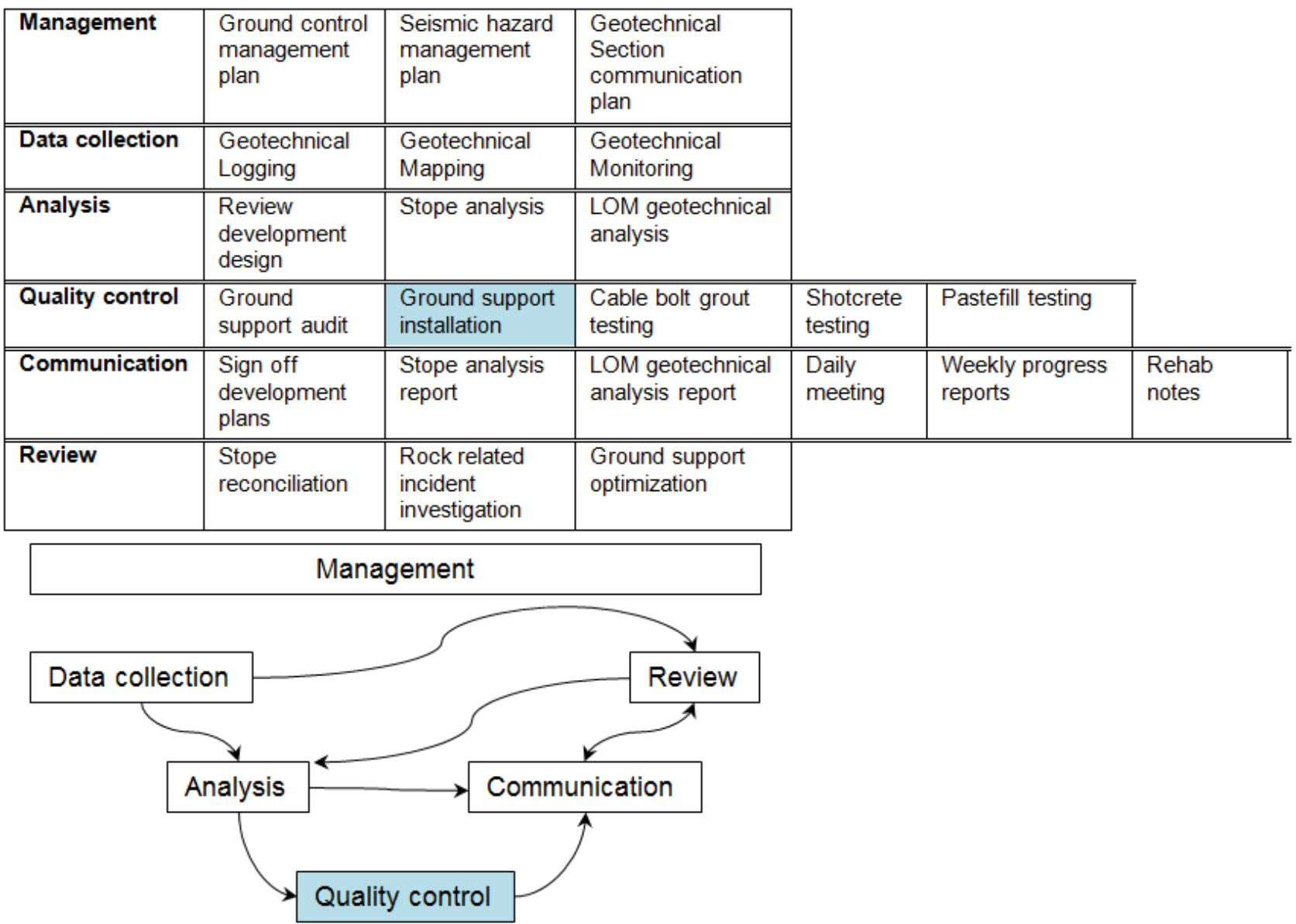

Figure 1 Geotechnical workflow diagram

The documentation required for each step in the workflow was identified. Existing documentation was reviewed where available, otherwise a new procedure was compiled. All documentation was compiled 
using the mine's current templates and document control systems. This was important to ensure the mine could take ownership of the information and easily update it.

\subsection{Department organisation}

A team performance plan was compiled for the geotechnical section. It states the team purpose, key result areas (safety, quality, stope dilution and design optimisation), and lists the team members. The plan also states the goals, strategies, actions, and key performance indicators for the section. An example of this is shown in Table 1.

Table 1 Goals and strategies of the geotechnical section

\begin{tabular}{lll}
\hline Goal & Strategies and action & Key performance indicators \\
\hline $\begin{array}{l}\text { Minimise dilution in } \\
\text { stopes caused by } \\
\text { rock instability. }\end{array}$ & $\begin{array}{l}\text { Provide geotechnical and paste fill } \\
\text { analyses for each stope and } \\
\text { stoping area with clearly stated } \\
\text { recommendations. }\end{array}$ & $\begin{array}{l}\text { Provide a risk analysis approach to stope } \\
\text { and paste fill analyses with an } \\
\text { understanding of acceptable levels of } \\
\text { dilution. Completed for each stope and } \\
\text { stoping area 1 month prior to extraction. }\end{array}$ \\
$\begin{array}{ll}\text { Eliminate exposure } \\
\text { of personnel and } \\
\text { equipment to rockfall } \\
\text { hazards. }\end{array}$ & $\begin{array}{l}\text { Check designs of every excavation, } \\
\text { recommend appropriate ground } \\
\text { support designs, regularly inspect } \\
\text { all excavations and check the } \\
\text { quality of ground support. }\end{array}$ & $\begin{array}{l}\text { QA/QC of all ground support, inspect all } \\
\text { mining areas at least once per week. } \\
\text { Reported upon monthly (or immediately if } \\
\text { it is a safety concern). Designs are checked } \\
\text { immediately. }\end{array}$ \\
$\begin{array}{l}\text { Optimise stope } \\
\text { designs. }\end{array}$ & $\begin{array}{l}\text { LOM planning and back-analysis of } \\
\text { all stopes for dilution. This } \\
\text { information is used for future } \\
\text { stope designs. }\end{array}$ & $\begin{array}{l}\text { Mining method selection and sequencing is } \\
\text { completed in accordance with the planning } \\
\text { schedule. Each stope is back-analysed as } \\
\text { soon as the CMS is available. Key }\end{array}$ \\
& $\begin{array}{l}\text { information is provided to the Mining } \\
\text { Engineers immediately. }\end{array}$ \\
\hline $\begin{array}{l}\text { Prevent inundation } \\
\text { to the underground } \\
\text { mine. }\end{array}$ & $\begin{array}{l}\text { Provide technical support to the } \\
\text { dewatering team. Ensure the mine } \\
\text { is not at risk of paste fill } \\
\text { inundation. }\end{array}$ & $\begin{array}{l}\text { Provide recommendations for risk } \\
\text { mitigation of inrush hazards. Provide } \\
\text { documentation to ensure paste fill }\end{array}$ \\
& $\begin{array}{l}\text { inundation does not occur as soon as the } \\
\text { certainty exists. }\end{array}$ \\
\hline
\end{tabular}

A skills matrix lists all the people in the geotechnical section, their job title, and the various skills and skill gaps, and training requirements for the section. This includes mandatory competencies for the mine site such as inductions and working at heights.

The geotechnical section follows a schedule to ensure the tasks are completed on time. The schedule includes data collection, QA/QC, monitoring and delivery of geotechnical designs. The diamond core logging schedule is governed by the geology department, who are responsible for diamond drilling. All other tasks are governed by the mining schedule and need to be updated following each mine planning meeting.

\subsection{Management plans}

There are two management plans for the geotechnical section at Bulyanhulu. The ground control management plan (GCMP) documents the history and evolution of the mine from a geotechnical perspective, describes the geotechnical setting, and explains the way in which rock-related hazards are managed. It makes reference to detailed information such as geology and procedures. 
The GCMP follows two simple rules in order to be relevant and accessible:

- Be concise: only include information regarding ground control management and include additional information such as ground support standards and detailed geology as appendices.

- Be accurate: the document should only reflect what is actually being done on site and not be aspirational.

The seismic hazard management plan (SHMP) outlines the key processes used in understanding and managing conditions that lead to seismic events and related risks. The aims of the SHMP are to:

- Improve the quality and consistency of seismic monitoring and analysis.

- Respond appropriately to seismic information.

- Improve the overall management of seismicity.

- Enable rapid and consistent response to major seismicity.

- Regulate and enforce risk management and re-entry protocols to be more effective.

\subsection{Procedures}

The following procedures were identified for amendment or addition by the geotechnical section at Bulyanhulu:

- Data collection: core logging.

- Data collection: geotechnical mapping.

- Monitoring: seismic system operation.

- Monitoring: seismic data analysis.

- Monitoring: extensometers.

- Monitoring: inspections.

- QA/QC: ground support installation.

- QA/QC: pull tests.

- QA/QC: cable bolt grout.

- QA/QC: paste fill.

- QA/QC: shotcrete.

- Design: stope analysis and reconciliation.

All procedures state the purpose, scope, task frequency, and describe the methods in detail to undertake the tasks effectively and safely. Furthermore, all procedures describe how to store the information and who to report to if the results fall outside of the stated tolerance levels.

Where possible the procedures include a hazard identification methodology that follows a structured process (Hartman 2004).

\subsection{Databases and reports}

Databases were set up for each task that involves the collection of data, i.e. core logging, mapping, extensometer readings, inspections and each of the QA/QC tasks. 
The geology section was already using an AcQuire database system for core logging. This was amended to incorporate the additional geotechnical data. At Bulyanhulu the geology section are measuring recovery and rock quality designation (RQD).

All other databases were set up in Excel with the required formulas in locked cells to prevent accidental deletion or overwriting. The monitoring and QA/QC databases were linked to worksheets containing graphs that measure quality and progress. The graphs can readily be copied into the weekly reports, providing relevant information to the mining department on the monitoring and QA/QC results. An example of these graphs is shown in Figure 2.
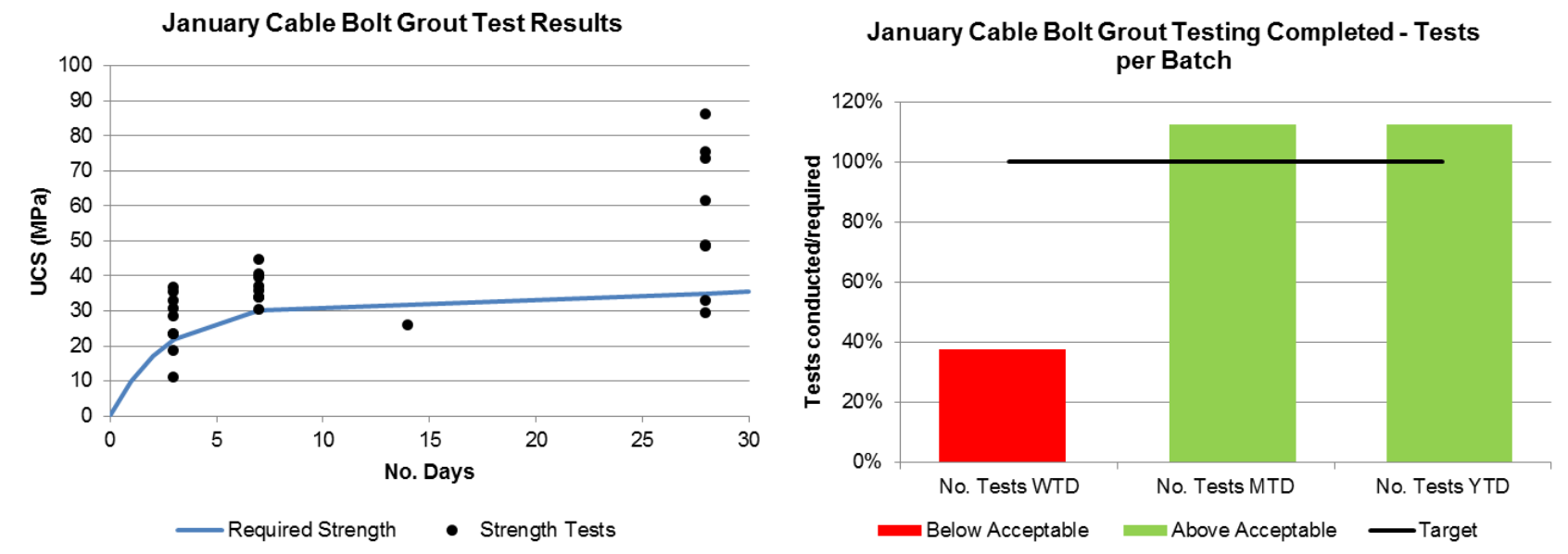

Figure 2 Example of graphs for weekly reports

The reports follow a set format that prompts the content required. They present results for monitoring, $Q A / Q C$, list the logging and mapping completed, and note any falls of ground that occurred during the reporting period. Periodic reporting helps to identify deficiencies or areas in which further work is required. This is more likely to cause positive action than verbal reporting.

The reports also provide action items for the mining department or other sections within the technical services department required to mitigate any operational geotechnical hazards.

Stope analysis reports are compiled for each longhole stope and presented to the mining engineers for input to their designs. Accurate stope stability analysis has been important at Bulyanhulu to manage the weak rock masses, or for blocky rock masses that are subject to stress damage and subsequent relaxation or loss of confining stress. The stope analysis reports ensure that the stability graph method was used in conjunction with a structural analysis.

\section{$3 \quad$ Results}

Logging and mapping data collection processes were simplified. Previously, data was being collected for both rock mass rating and the Norwegian Geotechnical Institute $Q$-system $(Q)$, but only $Q$ was being used in the analyses. Some information was collected twice by the geology and geotechnical sections. Geotechnical domains were unclear so these were revised taking into account $Q$ and unconfined compressive strength.

The geotechnical core logging process was revised so that the geology section first collects recovery and RQD as part of the geological logging process. They were provided guidelines on the selection of intervals to allow the geology and geotechnical staff to use the same interval table. The geotechnical section then logs the remaining $Q$ parameters in the same interval data table and structural data in a separate point data table. The interval table is used for rock mass classification and the point data table is used for stereographic analysis. The geotechnical domain is recorded in both tables, instead of rock type.

The mapping process was revised to collect only the data necessary for input into analyses. The process is similar to that for core logging, with domain mapping recorded in an interval data table and structural data 
in a point data table. The geotechnical domain, fracture count, and damage rating are collected in domain mapping. The fracture count from mapping is used to estimate RQD where drill hole data is sparse. Once a reasonable data density is achieved, no additional data is collected. The geologists collect all the other relevant information required for analysis as part of geological mapping.

Damage mapping was also incorporated into the mapping procedure, to be completed at certain times during the mining sequence of a stoping panel. Damage mapping is critical for the calibration of numerical models. Numerical modelling using Map3D is conducted at Bulyanhulu to assess mining-induced stresses in the stoping panels and to evaluate alternative mining sequences.

The key benefits of refining the data collection processes are improved efficiency in data collection and the systematic storage of data in central databases. This allows for improved access for use in analyses and for an increased focus on analysis and design.

The monitoring processes were altered with the purpose of using the information to check designs and mitigate geotechnical risks. A procedure for seismic system operation was already in place; however, a procedure for seismic data analysis and interpretation was required to optimise use of the monitoring system and mitigate seismic risk, in conjunction with the SHMP.

The procedure for geotechnical inspections was altered to include stope brows as well as active headings and pre-stope inspections, and to include a simple damage rating system after Sandy et al. (2010). The rating system allows for a somewhat objective and consistent approach to determining levels of damage and providing guidance for rehabilitation. It also outlines the steps required to have the rehabilitation completed. Information for each inspection is entered into a database that also serves as a tracking system for the rehabilitation work.

Procedures were already in place for $Q A / Q C$ at Bulyanhulu. These documents were reviewed to comply with current industry standards and the database and reporting processes were improved. The QA/QC results are now reported regularly for the immediate identification of any issues related to the installation of ground support. This triggers further investigation and remedial works as appropriate.

Aside from the weekly reports provided to the mining department, stope analysis reports are also provided regularly. These reports are intended to incorporate relevant information taken from the data collection processes, lessons learnt from monitoring and back-analysis, and numerical modelling results. The process ensures that the appropriate data is used for analysis, stresses are estimated from numerical modelling, and that a structural analysis is also completed. The design parameters provided to the mining engineers will be accurate and optimal to result in decreased dilution.

The stope analysis procedure is used as a training manual to provide training for the less experienced geotechnical staff and free up time for others to complete more complex geotechnical analyses such as the optimisation of ground support and life-of-mine studies.

Fall of ground reports are also provided by the geotechnical section. They were revised to include information on failure mechanisms and the condition of the ground support. This is a critical part of the feedback loop within the geotechnical workflow diagram.

\section{$4 \quad$ Discussion and conclusion}

The geotechnical section at Bulyanhulu was able to improve geotechnical input into mine designs and overall sustainability of the geotechnical section through improved efficiency and communication to a number of geotechnical processes. This outcome was achieved through a combination of improving the group's organisational structure, documentation, and through training and coaching to implement any changes effectively. These outcomes were considered to be consistent with the project expectations.

The mine designs were improved for stope analysis and back-analysis. The outcomes of the project should also lead to the improvement of long-term mine designs. 
Risk mitigation was another major focus for the project. The improved processes for geotechnical engineering allow for consistent reporting and management of geotechnical risks. The processes for risk mitigation are documented in the management plans.

Another outcome of the project was the overall improvement in personnel motivation within the geotechnical section. With the introduction of databases for all data collection, QA/QC, and monitoring tasks, everything is now measurable. Personal key performance indicators are clear and concise for each staff member. Unnecessary data collection has been eliminated. Awareness was increased and complacency decreased through the process of training and coaching.

\section{Acknowledgement}

The authors would like to acknowledge Acacia Mining Plc for their approval to publish this paper.

\section{References}

Chamberlain, CM 2003, 'Geology and genesis of the Bulyanhulu Gold Deposit, Sukumaland Greenstone Belt, Tanzania' PhD thesis, University of London.

Hartman, W 2004, 'The risk management process for practicing geotechnical engineers', AusIMM Bulletin, The Australasian Institute of Mining and Metallurgy, Melbourne, $15 \mathrm{p}$.

Sandy, MP, Sharrock, G, Albrecht, J \& Vakili, A 2010, 'Managing the transition from low stress to high stress conditions', Proceedings of the Second Australasian Ground Control in Mining Conference, The Australasian Institute of Mining and Metallurgy, Melbourne. 